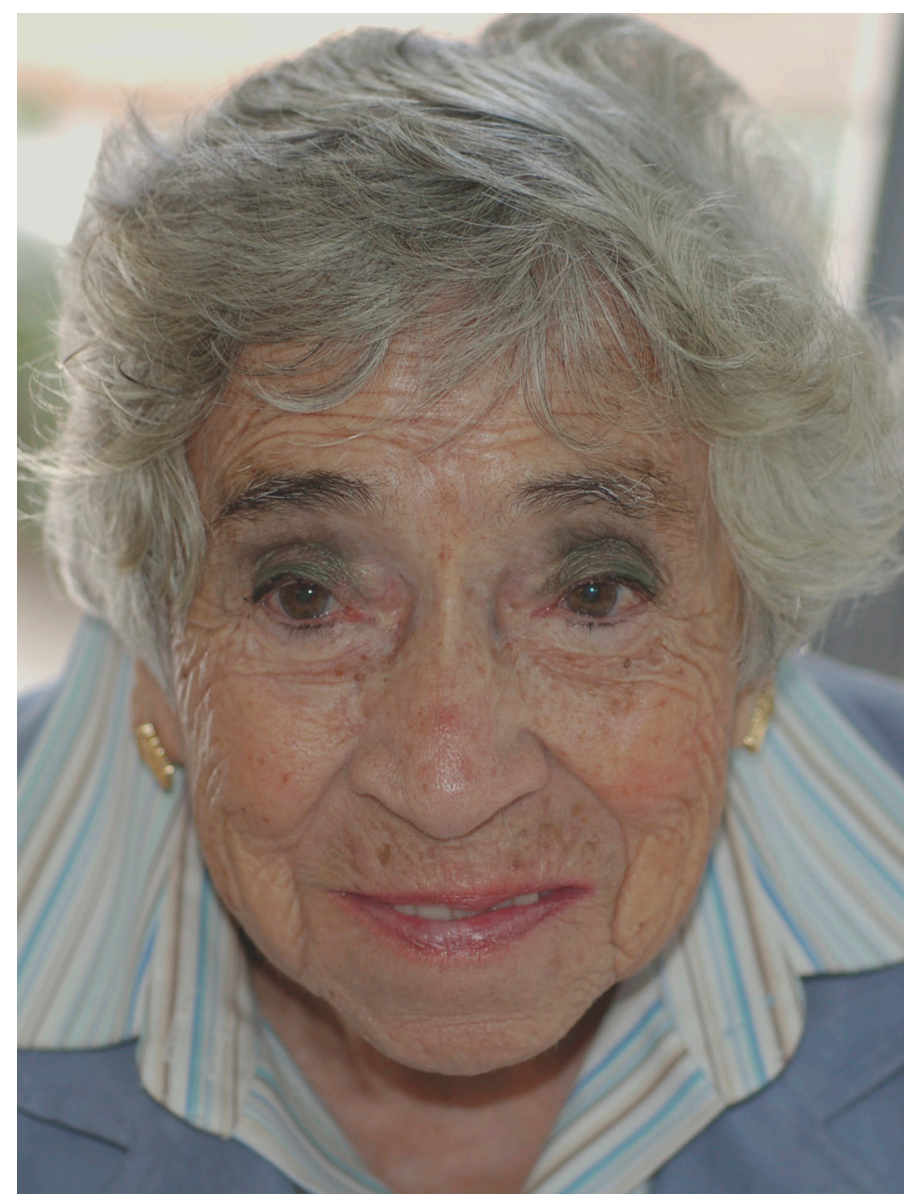

\title{
LUZ MARÍA VILLARREAL DE PUGA (1913-2013)
}

Luz María Villarreal Millán, mejor conocida como la "Maestra Puga", nació el 8 de marzo de 1913 en la Ciudad de México, Distrito Federal, en donde vivió y estudió hasta que se graduó como profesora normalista en el Colegio de Las Vizcaínas.

Durante varios años se desempeñó como secretaria, pero dejó de trabajar temporalmente en 1942, cuando contrajo matrimonio con el Sr. Felipe González Ordorica, de quien se separaría unos años más tarde; como fruto de esta unión nació su hija Luz María González Villarreal.

$\mathrm{Su}$ afición por la botánica se inició gracias a las enseñanzas y motivación que recibió de Irene Baeza, que fue su maestra en el Colegio de las Vizcaínas y con 
quien entabló una entrañable amistad. Esta inquietud no la pudo desarrollar plenamente sino hasta que, después de contraer segundas nupcias con el Ingeniero Luis Puga Robles Gil, se mudó a la ciudad de Guadalajara a la edad de 47 años.

A principios de la década de los sesenta hizo una especialización en Biología en la Escuela Normal Superior "Nueva Galicia" de Guadalajara y posteriormente inició sus actividades docentes dando clases de biología, zoología y botánica en las escuelas preparatorias de la Universidad de Guadalajara, actividad que desempeñó de 1965 a 1972, cuando fue nombrada Maestra de Tiempo Completo en la Escuela de Agricultura de la Universidad de Guadalajara, en donde impartió las cátedras de Botánica General y Botánica Sistemática hasta 1980, año en que asumió la Dirección del Instituto de Botánica. Su labor como maestra fue tan fecunda que influyó en la formación de numerosas generaciones de ingenieros agrónomos y logró motivar a varios de sus alumnos para que siguieran el camino de la botánica.

Le correspondió a la Maestra Luz María Villarreal de Puga vivir muy de cerca el desarrollo del Instituto de Botánica de la Universidad de Guadalajara, desde sus primeros años de actividad hasta su consolidación como una institución de investigación reconocida a nivel nacional e internacional. La Maestra Puga se incorporó al Instituto de Botánica en 1960 como trabajadora voluntaria; más tarde, entre 1965 y 1980 se desempeñó como Secretaria y en 1980 asumió la Dirección del Instituto, cargo que conservó hasta 1992, en que fue nombrada Directora Honorífica Vitalicia del mismo.

Durante su gestión en el Instituto de Botánica impulsó los estudios florísticos y de vegetación en Jalisco, se preocupó por la formación de recursos humanos y lo consolidó como una institución de investigación interesada en el conocimiento y conservación de los recursos naturales del estado.

Luz María Villarreal de Puga inició la colecta de ejemplares botánicos en 1960, durante la excursión del Primer Congreso Mexicano de Botánica. Posteriormente, durante las salidas al campo organizadas por la Sociedad Botánica del Estado de Jalisco, colectó con entusiasmo para formar el herbario del Instituto de Botánica.

Su colección supera los 17000 números, en ésta se incluyen plantas de Jalisco, de otros estados de la República Mexicana y aún del extranjero. Uno de sus descubrimientos más interesantes fue el del género Ledenbergia (Phytolaccaceae) en Jalisco y jugó un papel preponderante en los descubrimientos de los maíces silvestres (teosintes) Zea perennis en Ciudad Guzmán y Zea diploperennis en la Sierra de Manantlán, al motivar y apoyar a sus estudiantes en las exploraciones que culminaron con estos hallazgos.

Durante las últimas décadas del Siglo XX, la Maestra Villarreal de Puga realizó un extraordinario esfuerzo en favor de la conservación de los recursos naturales 
del estado de Jalisco. Fue la principal promotora para la formación de la Reserva de la Biosfera de la Sierra de Manantlán, para la protección de los bosques de esta sierra y del maíz perenne.

La inquietud de la Maestra Luz María Villarreal de Puga por el desarrollo y difusión de las ciencias biológicas, así como su afán por la conservación de los recursos naturales y el respeto a los derechos de la mujer se ven reflejados en su participación en 12 sociedades científicas y asociaciones no gubernamentales; entre las que se encuentran la Sociedad Botánica del Estado de Jalisco, la Sociedad Orquidófila de Guadalajara, la Sociedad Botánica de México y la International Association for Plant Taxonomy. En 1981 fue nombrada Socia Honoraria de la Sociedad Botánica de México y en dos ocasiones, en 1981 y 1988 ha recibido reconocimientos de la Sociedad Botánica de México por el fomento a los estudios florísticos en el occidente de México.

Por su extraordinaria labor educativa, el impulso que dio a la investigación botánica, así como por sus esfuerzos por proteger los recursos naturales del estado de Jalisco, la maestra Luz María Villarreal de Puga se hizo acreedora a numerosos reconocimientos, algunos de los más importantes son:

La entrega de la medalla de plata en el Año Internacional de la Mujer (1975), en 1990 fue reconocida como Maestra Emérita por la Universidad de Guadalajara, recibió el nombramiento de Directora Honorífica Vitalicia del Instituto de Botánica de la Universidad de Guadalajara (1992), el Dr. Rogers McVaugh dedicó en su honor el Volumen 13 de la Flora Novo-Galiciana (1993); se hizo acreedora al premio al Mérito Nacional Forestal y de la Vida Silvestre, en la categoría de Fomento de Flora en 1994; en el año 2004 la Universidad de Guadalajara le otorgó el título de Doctora Honoris Causa; además, 13 especies y una variedad de plantas vasculares llevan su nombre como reconocimiento a su labor en el estudio de la flora del estado de Jalisco.

La muy apreciada Maestra Puga falleció el lunes 11 de noviembre del año 2013, ocho meses después de cumplir 100 años de vida fructífera. Su profundo amor por la naturaleza su generosidad, su pasión por la enseñanza y su invaluable estímulo a la investigación, dejaron una huella profunda en quienes tuvimos el privilegio de ser sus alumnos y/o sus amigos.

Sergio Zamudio Ruiz Instituto de Ecología, A. C. 
